\title{
Goal conflict in chronic pain: Daily Reconstruction Method
}

\author{
Nathalie Claes ${ }^{\text {Corresp.. }}{ }^{1,2}$ ， Johan W S Vlaeyen ${ }^{1,3}$ ， Emelien Lauwerier ${ }^{2,4}$, Michel Meulders ${ }^{5,6}$, Geert Crombez ${ }^{2,7}$ \\ ${ }^{1}$ Research Group Health Psychology, Katholieke Universiteit Leuven, Leuven, Belgium \\ 2 \\ 3 Department of Clinical Psychological Science, University of Maastricht, Maastricht, The Netherlands \\ 4 Department of Public Health and Primary Care, Ghent University, Ghent, Belgium \\ 6 Research Group on Quantitative Psychology and Individual Differences, Katholieke Universiteit Leuven, Leuven, Belgium \\ 7 Centre for Pain Research, University of Bath, Bath, United Kingdom \\ Corresponding Author: Nathalie Claes \\ Email address: nathalie.claes@kuleuven.be
}

Background. When suffering from chronic pain, attempts to control or avoid pain often compete with other daily activities. Engaging in one activity excludes engaging in another, equally valued activity, which is referred to as "goal conflict". As yet, the presence and effects of goal conflicts in patients with chronic pain remain poorly understood.

Methods. Therefore, this study systematically mapped the presence and experience of goal conflicts in patients with fibromyalgia compared to healthy controls. Forty patients and 37 controls completed a semi-structured interview in which they first reconstructed the previous day, identified conflicts experienced during that day, and classified each of the conflicting goals in one of nine goal categories.

Results. Additionally, they assessed how they experienced the previous day and the reported conflicts. Results showed that patients did not experience more goal conflicts than healthy controls, but that they did differ in the type of conflicts experienced. Compared to controls, patients reported more conflicts related to pain, and fewer conflicts involving work-related, social or pleasure-related goals. Moreover, patients experienced conflicts as more aversive and more difficult to resolve than control participants.

Discussion. This study provides more insight in the dynamics of goal conflict in daily life, and indicates that patients experience conflict as more aversive than controls, and that conflict between pain control (and avoidance) and other valued activities is part of the life of patients. 


2

4

21

\section{GOAL CONFLICT IN CHRONIC PAIN: DAILY RECONSTRUCTION METHOD}

Nathalie Claes, $\mathrm{PhD}^{1,2}$, Johan W.S. Vlaeyen, $\mathrm{PhD}^{1,3}$, Emelien Lauwerier, $\mathrm{PhD}^{2,4}$, Michel

Meulders, $\mathrm{PhD}^{5,6}$, and Geert Crombez, $\mathrm{PhD}^{2,7}$

${ }^{1}$ Research Group Health Psychology, KU Leuven, Belgium

${ }^{2}$ Department of Experimental-Clinical and Health Psychology, Ghent University, Belgium

${ }^{3}$ Department of Clinical Psychological Science, Maastricht University, The Netherlands

${ }^{4}$ Department of Public Health and Primary Care, Faculty of Medicine and Health

Sciences, Ghent University, Belgium

${ }^{5}$ Center for Information Management, Modeling and Simulation, KU Leuven, Belgium

${ }^{6}$ Research group on Quantitative Psychology and Individual Differences, KU Leuven, Belgium

${ }^{7}$ Centre for Pain Research, University of Bath, United Kingdom

The work was conducted at Ghent University, Ghent, Belgium

15

6

Corresponding author: Nathalie Claes, Research Group on Health Psychology, Department of

9 Psychology, University of Leuven, Tiensestraat 102, box 3726, 3000 Leuven, Belgium. E-mail:

Nathalie.claes@kuleuven.be, T: +32(0)16 3258 85, F: +32(0)16 326144. 


\section{Abstract}

28 Background. When suffering from chronic pain, attempts to control or avoid pain often compete

29 with other daily activities. As yet, the presence and effects of such goal conflicts in patients with

30 chronic pain is poorly understood.

31 Methods. Therefore, this study systematically mapped the presence and experience of goal

32 conflicts in patients with fibromyalgia compared to healthy controls. Forty patients and 37

33 controls completed a semi-structured interview. First, participants reconstructed the previous day

34 and identified goal conflicts. Second, each goal of the conflict was classified in one of nine goal

35 categories. Third, the experience of that day and, in particular, of the reported conflicts, was

36 assessed.

37 Results. Results showed that patients did not report more goal conflicts than healthy controls.

38 However, compared to controls, patients reported more conflicts related to pain, and fewer

39 conflicts involving work-related, social or pleasure-related goals. Patients also reported conflicts

40 being more aversive and being more difficult to resolve than control participants.

41 Discussion. This study provides more insight in the dynamics of goal conflict in daily life, and

42 indicates that conflict is experienced as more aversive by patients compared to controls, and that 43 conflict between pain control (and avoidance) and other activities is part of the life of patients. 
47

\section{Introduction}

The Fear-Avoidance model of chronic pain (Vlaeyen \& Linton, 2012; Vlaeyen \& Linton, 2000) essentially describes two possible cognitive-behavioral responses to pain. On the one hand, the individual may appraise pain as nonthreatening, and gradually resumes activities. On the other hand, pain may be interpreted as a sign of injury, which in turn may lead to pain-related fear, resulting in avoidance behavior and vigilance. When such pattern of avoidance persists, it may bring along depression, social isolation, disability or reduced participation in daily life activities. Although there is evidence validating these behavioral responses (Leeuw et al., 2007; Zale et al., 2013; Wertli et al., 2014), challenges remain (Crombez, Eccleston, Van Damme, Vlaeyen, \& Karoly, 2012).

There is a call for including a broad motivational context into the model: Patients with chronic pain often not only want to avoid pain, but may also want to pursue other valued activities, such as socializing with friends (Crombez et al., 2012; Vlaeyen, Crombez, \& Linton, 2009). Different relations may exist between pain avoidance goals and other goals. Avoiding pain may facilitate pursuing other activities ("goal facilitation"), but it may also interfere with goals ("goal interference" ; Boudreaux \& Ozer, 2012; Riediger \& Freund, 2004). We may expect that goal interference is often preceded by the experience of goal conflict. Indeed, goal conflicts arise because of incompatible attainment strategies or resource constraints (e.g., time) and is characterized by a behavioral indecisiveness (Lewin, 1935; Miller, 1944; Riediger \& Freund, 2004). The responses described by the Fear-Avoidance model can be reframed in motivational terms: the pattern of avoidance may correspond with prioritizing the goal to control pain at the cost of other goals, whereas the confrontational response may reflect prioritizing and engaging in other life goals, despite pain (Crombez et al., 2012; Lauwerier et al., 2012; Van Damme, 
70 Crombez, \& Eccleston, 2008; Vlaeyen, Morley, \& Crombez, 2016). Although there is research

71 on avoidance and confrontation, there is almost no research on goal conflict. In general, research

72 has demonstrated that experiencing goal conflict negatively affects well-being (Boudreaux \&

73 Ozer, 2012; Emmons \& King, 1988). Karoly and colleagues (2008) also reported that patients

74 experience more goal frustration and more goal conflict than control participants. Furthermore,

75 goal conflict has been associated with more pain-related fear (Karoly et al., 2008), and with a

76 greater increase in pain from morning to evening (Hardy, Crofford \& Segerstrom, 2011).

77 However, the potentially detrimental effects of goal conflict on well-being have not always been

78 replicated (Segerstrom \& Solberg Nes, 2006), suggesting that contextual factors may play a role

79 (Gorges, Esdar \& Wild, 2014).

80 Here, we seek to further our understanding of goal conflict in patients with chronic pain.

81 The main objective was exploratory in nature, and focuses on mapping the presence and

82 experience of goal conflicts in patients with fibromyalgia and in healthy controls. Research

83 questions were (1) do patients experience more goal conflict in daily life than healthy

84 participants? ; (2) do patient and healthy participants differ in the type of conflicts they

85 experience?; (3) which goals commonly compete with pain-related goals?; (4) do patients and

86 controls differ in the experience and context of conflict?; and (5) can core constructs of the Fear-

87 Avoidance model or individual differences predict the number of (pain-related) goal conflicts?

88 To this purpose, patients with fibromyalgia and matched healthy controls were invited to

89 participate in a semi-structured interview based on the Daily Reconstruction Method (Kahneman

90 et al., 2004) in which patients first reconstructed the previous day in keywords. Next, participants

91 identified conflicts experienced during the previous day. Subsequently, participants classified

92 each goal of their conflict in one of the pre-defined categories. Finally, participants assessed the 
93 experience of maximally three conflicts and rated their pain, fatigue, emotions, and overall

94 experience of that day. Participants also completed a series of questionnaires.

\section{$2 \quad$ Materials and Methods}

\section{$97 \quad 2.1 \quad$ Participants}

The current study is part of the Pain-Attention-Motivation Project 1 (PAM-I-Project;

99 Claes et al., 2015), consisting of three independent studies investigating attentional and

100 motivational processes in patients with chronic pain. For an overview of the project, the

101 participant inclusion process and overview of the measurements, see Claes et al., 2015. The

102 PAM-I-Project was approved by the Medical Ethical Committee of Ghent University Hospital 103 (registration number B670201421583). All participants received reimbursement for their 104 expenses.

\subsubsection{Patients with fibromyalgia}

Patients with fibromyalgia seeking health care between the ages of 18-65 years were recruited in two ways: (a) From July 2011 until August 2014, posters were placed in the waiting room of the Multidisciplinary Pain Centre of Ghent University Hospital, and medical doctors informed patients about the possibility to participate in research. Eighty-four interested patients

110 with fibromyalgia provided their information to be contacted for participation; (b) From August

1112014 onwards, patients from the Multidisciplinary Pain Centre are asked to complete online

112 questionnaires at intake. Upon completion of these questionnaires, participants provide their

113 contact details for research purposes. Fourteen individuals with fibromyalgia left their contact

114 information. In sum, both recruitment methods led to a total number of 98 individuals with 115 fibromyalgia who could be contacted. Inclusion criteria were: being diagnosed with 
116 Fibromyalgia, fluency in the Dutch language, normal or corrected-to-normal eyesight, normal or

117 corrected-to-normal hearing. Participants were excluded if they suffered from neurological

118 problems (e.g., epilepsy), or reduced tactile sensitivity as this was relevant for another, but

119 unrelated study of the PAM-I-project.

120 We contacted $90(91.8 \%)$ of the 98 candidates until the predetermined number of 40

121 participants was reached. Fifty $(51 \%)$ of the 90 patients did not wish to participate. Most

122 common reasons for non-participation were distance to the faculty, time constraints, or

123 aggravation of complaints. In total, 40 patients with fibromyalgia (three males) participated.

124 Patients were between 29 and 64 years of age $(M=45.8, S D=9.22)$. The majority of patients

125 was married $(57.5 \%)$, or cohabiting (5\%). Fifteen $(37.5 \%)$ patients received higher education.

126 Only $22.5 \%$ of patients was employed, $5 \%$ was retired, and $7.5 \%$ was unemployed. The

127 remaining patients received health insurance $(17.5 \%)$ or disability $(47.5 \%)$ benefits. The mean

128 reported duration of patients' pain was $14.5 \pm 12.01$ years.

\section{$129 \quad$ 2.1.2 Healthy control participants}

130 We recruited control participants matching sex, age and educational level of the

131 fibromyalgia patients via frequency sampling. Healthy participants were recruited in several

132 ways: advertisements in local newspapers or social media, flyers distributed around the

133 university campus and public venues. Hundred and eighty-one candidate individuals expressed

134 their willingness to participate in research and left their contact information. We contacted 135 control participants based on the recruitment of patients: we randomly contacted a candidate

136 control participant that matched for sex, age and educational level of the patient participants until

137 we found enough candidates willing to participate. We contacted 55 (30.39\%) of these 181 
138 candidates; $126(69.61 \%)$ of candidates were not contacted, as they did not match the participant

139 profile (age, sex, educational level) or a sufficient number of control participants was reached.

140 Fourteen out of $55(23.6 \%)$ did not wish to participate. Most common reasons for non-

141 participation were suffering from a chronic illness and lack of time. In total, 41 controls

142 participated. Inclusion and exclusion criteria were the similar, except for the following: fulfilling

143 ACR criteria for fibromyalgia (Wolfe et al., 2010), and suffering from pain of a severe intensity

144 (category II, III or IV, see further) according to the criteria of Von Korff, Ormel, Keefe, and

145 Dworkin (1992). Three participants suffered from pain of a severe intensity, another met the

146 diagnostic criteria for fibromyalgia. These four (1\%) participants were excluded from analyses.

147 The final sample comprised of 37 healthy controls (four males), with a mean age of $45.92 \pm$

14810.14 years. Most control participants were either married $(29.7 \%)$ or living together with a

149 partner (16.2\%). 40.5\% finished higher education. The majority of control participants was in

150 paid employment or received education (62.2\%), 5.4\% was retired, and $27 \%$ was unemployed.

151 One participant was in unpaid employment, and another received health insurance benefits.

152 Control participants were matched to patient participants, as they did not significantly

153 differ from patient participants in terms of gender, $t(75)<1, p=.619$, age, $t(75)<1, p=.957$,

154 level of education, $t(75)=-1.31, p=.194$, and in marital status, $\mathrm{t}(75)<1 ; \mathrm{p}=.419$. However,

155 patients were more often unemployed or receiving disability benefits than control participants, $156 \mathrm{t}(75)=-6.775, \mathrm{p}<.0001$.

157 All participants provided verbal and written informed consent and were informed that 158 participation was voluntary and could be stopped at any point in time, without negative 159 consequences. 


\section{$160 \quad 2.2 \quad$ Procedure}

Participants were invited for an individual appointment at Ghent University, which took approximately three hours. Before the individual appointment, participants were asked to complete a sociodemographical information sheet (i.e., age, gender, profession, education level, work status) and several questionnaires. Patients additionally provided information on their pain problem, and completed questionnaires (for an overview of all questionnaires, see the PAM-IProtocol). Seventy participants filled in these questionnaires online, seven participants filled in a

167 paper version. Questionnaires were included either for descriptive purposes (e.g., sociodemographical information; pain severity), assessing inclusion and exclusion criteria (e.g., diagnostic criteria for Fibromyalgia; pain severity), and/or exploring the predictive value of the constructs (e.g., DASS; PCS; ECIP) in the experience of goal conflict. As this study was part of a large project, a number of questionnaires were not included in the analysis of this study. based on the Daily Reconstruction Method (DRM; Kahneman et al., 2004). This semi-structured interview was constructed by a group of (pain research) experts, and was extensively piloted in patients prior to the study. Interviewers (N.C., N.D., E.D.M., J.M; all female) were extensively trained in using the standardized interview protocol. During the interview, participants reconstructed their previous day, next reported the number of goal conflicts experienced during that day, categorized the goals involved, and assessed the emotions and overall experience of the conflict(s). Lastly, participants assessed their pain, fatigue, emotions, and general experience of

180 that day. The interview lasted about 60-90 minutes per participant.

\section{$181 \quad 2.3 \quad$ Materials and measures}




\section{$182 \quad$ 2.3.1 Sociodemographic information}

183 For descriptive purposes, participants provided information on gender, age, education,

184 employment, and marital status. Patients also provided information on the duration and treatment

185 of their pain problem.

\section{$186 \quad$ 2.3.2 Diagnostic Criteria for fibromyalgia}

187 Participants completed the Dutch version of the ACR Criteria for fibromyalgia (Geenen

188 \& Jacobs, 2010; Wolfe et al., 2010), which consists of two parts. In the first part, respondents

189 indicate the painful locations on a manikin. A widespread pain index (WPI) is calculated by

190 counting the number of reported painful body regions. The score varies between zero and 19. in

191 the second part, respondents report on the severity of their cognitive symptoms and the presence

192 of extra somatic symptoms (e.g., headache, fever, tinnitus) using a four-point scale $(0=$ absent; 3

$193=\mathrm{a}$ lot). The sum of these items results in a Symptom Score (SS), ranging from zero to 12.

194

195

196

197

198

200

201

202

203

204

\subsubsection{Pain Severity}

To assess pain severity, the Graded Chronic Pain Scale (GCPS; Von Korff et al., 1992) was completed. The GCPS was used to address the exclusion criteria for control participants. Items measuring pain intensity are: current pain intensity, worst pain intensity, and average pain intensity in the past six months, using an 11-point scale $(0=$ no pain; $10=$ pain as bad as could be). Items measuring pain disability are: the number of days that the participant was unable to perform his/her usual activities (work, school, or housework) during the past six months, the extent of interference with daily activities, the ability to take part in recreational, social and family activities, and the ability to work. The latter three items are scored using an 11-point scale ( $0=$ no interference; $10=$ unable to carry on any activities). Based on the pain intensity and interference, respondents can be classified in five categories: (1) Grade 0: no pain in the past six 
205 months; (2) Grade I: low pain intensity and low disability; (3) Grade II: high pain intensity, but 206 low disability; (4) Grade III: highly disabling, moderately limiting pain; (5) Grade IV: highly 207 disabling, severely limiting pain. The GCPS has been shown to be a valid and reliable instrument 208 (Von Korff et al., 1992).

\subsubsection{Pain Catastrophizing}

210 To measure the frequency of catastrophic thoughts and feelings experienced when in

211 pain, participants completed the Dutch version of the Pain Catastrophizing Scale (PCS; PCS-DV;

212 Crombez, Eccleston, Baeyens, \& Eelen, 1998; Sullivan, Bishop, \& Pivik, 1995). The PCS

213 comprises of 13 items, and is scored using a 5-point scale ( $0=$ not at all ; $4=$ always). The PCS

214 yields a total score between zero and 52, and three subscale scores: rumination (e.g., "I keep

215 thinking about how much it hurts"), magnification (e.g., "I become afraid that the pain will get

216 worse"), and helplessness (e.g., "I feel I can't go on"). Internal consistency and validity of the

217 PCS are shown to be good (Sullivan et al., 1995; Van Damme, Crombez, Bijttebier, Goubert, \&

218 Van Houdenhove, 2002). Cronbach's $\alpha$ for the PCS in this study was .94.

\section{$219 \quad$ 2.3.5 Depression, Anxiety and Stress}

220 Participants filled in the Depression Anxiety and Stress Scales (DASS; Lovibond \&

221 Lovibond, 1995a,b), which consists of 42 items describing negative symptoms. Respondents are

222 asked to rate the extent to which they have experienced each of the symptoms during the past

223 week using a four-point numerical scale ( $0=$ not at all applicable; $3=$ definitely applicable).

224 Scores for the Depression, Anxiety, and Stress subscales are calculated by summing the 225 corresponding items (14 per subscale). Example items are "I felt I was pretty worthless" for 226 Depression, "I felt terrified" for Anxiety, and "I found that I was very irritable" for Stress. 
227 Internal consistency and validity of the DASS are good (Antony et al., 1998). In this study, we

228 found a Cronbach's $\alpha$ of .94 for Stress, .89 for Anxiety, and .95 for Depression.

229

230

231

232

233

234

235

236

237

238

239

240

241

242

243

244

\subsubsection{Trait anxiety}

To measure trait anxiety, the Dutch translation of the trait version of the Spielberger State-Trait Anxiety Inventory (STAI; Spielberger, Gorsuch, \& Lushene, 1970), called the ZelfBeoordelings Vragenlijst (ZBV; Van der Ploeg, 1980), was completed. The STAI trait version consists of 20 items, each rated on a four-point numerical scale $(1=$ no anxiety; $4=$ very anxious). The total score ranges between 20 and 80 , with scores of 50 or above labeled as anxious. The STAI has shown to be valid and reliable (Spielberger, Gorsuch \& Lushene, 1970; Van der Ploeg, 1980). Cronbach's $\alpha$ for this study was .94.

\subsubsection{Cognitive intrusions}

The Experience of Cognitive Intrusion Pain scale (ECIP) was used to measure the extent to which the experience of pain interferes with thinking when experiencing pain (Attridge et al., 2015). The scale has ten items, all scored on a 7 -point scale $(0=$ not at all applicable; $6=$ highly applicable). Items focus on interruption by pain (e.g., "pain interrupts my thinking"), ruminative thoughts on pain (e.g., "pain goes around and around in my head"), and control by pain (e.g., "I can't push pain out of my thoughts"). The total score ranges from zero to 60 , and is obtained by summing all items. Cronbach's $\alpha$ for the ECIP in this study was .97.

\subsubsection{Positive and negative affectivity}

Participants completed a Dutch version of the trait version of the Positive and Negative Affectivity Scale (PANAS; Engelen, De Peuter, Victoir, Van Diest, \& Van Den Bergh, 2006; Watson, Clark, \& Tellegen, 1988). The PANAS consists of 20 items, ten positive affect words 
249 (e.g., interested, cheerful), and ten negative affect words (e.g., sad, guilty). Respondents used a 250 5-point Likert scale $(1=$ very slightly or not at all; $5=$ extremely $)$ to indicate the extent to which

251 they generally experience each of the emotions. This Dutch version of the PANAS is shown to 252 be a reliable and valid instrument (Engelen et al., 2006). The Cronbach's $\alpha$ was .87 for the 253 positive scale, and .90 for the negative scale.

\section{$254 \quad$ 2.3.9 Pain Disability}

To measure the degree to which pain interferes with the ability to participate in daily life, 256 we used the Pain Disability Index (PDI; Pollard, 1984). This questionnaire consists of seven items assessing the disability in each of the following domains: family and home responsibilities, recreation, social activity, occupation, sexual behavior, self-care, and life-supporting activity is considered a reliable and valid instrument to study pain-related disability (Tait, Chibnall \&

261 Krause, 1990). In the current study, we found a Cronbach's $\alpha$ of .87 for the PDI.

\section{2.3.10 Vigilance}

Patient participants completed the Dutch version of the Pain Vigilance and Awareness Questionnaire (PVAQ), which contains 16 items that measure the respondent's vigilance for painful sensations during the last two weeks (McCracken, 1997; Roelofs, Peters, Muris, \& Vlaeyen, 2002). Each item is rated on a six-point numerical scale $(0=$ never; $5=$ always $)$. The total score is calculated by summing all items, resulting in a total score ranging from zero to 80 . The validity and reliability of the PVAQ has shown to be good (Roelofs et al., 2002; Roelofs, Peters, McCracken, \& Vlaeyen, 2003). Cronbach's $\alpha$ in this study was .87. 
270

271

272

273

274

275

276

277

278

279

280

281

282

283

284

285

286

287

288

289

290

291

292

\subsubsection{Pain-related fear}

To assess four components - fearful appraisal of pain, cognitive anxiety, psychological anxiety, and escape and avoidance behavior — of pain-related fear, patient participants completed the Pain Anxiety Symptoms Scale (PASS; McCracken, Zayfert, \& Gross, 1992). The PASS contains 40 items scored on a 6-point scale ranging from 0 ("never") to 5 ("always"). The PASS has been shown to be reliable (Burns et al., 2000; Roelofs et al., 2004). For the PASS, we found a Cronbach's $\alpha$ of .86 .

\subsubsection{Semi-structured interview}

Participants completed a semi-structured interview based on the Day Reconstruction Method (DRM) of Kahneman et al.(2004), which was originally developed to study activities and affective experiences of the previous day. The semi-structured interview used here had the goal to activate memories of the previous day by letting participants reconstruct their day, and to enable them to identify and report on experiences of goal conflict.

Reconstruction of previous day. First the interviewer explained the objective and procedure of the interview to participants. Participants indicated the date and day of the previous day, as well as the time they woke up in the morning and the time they went to bed. In contrast with the original DRM-where participants independently reconstruct their previous day by means of an anonymous diary - the interviewer asked participants to verbally report on the activities they had undertaken the previous day. The interviewer prompted participants to freely report the activities of the previous day, and to take the time needed to reflect on that day and on possible key words describing these activities. Participants were asked to report on activities during the morning (from waking until noon), afternoon (noon until about 18:00), and evening (from about 18:00 until going to bed). An activity usually varied between 15 minutes and two 
293 hours, and often started when someone new joined in, or when going to another location. The

294 interviewer stressed that participants could express themselves in a way they felt comfortable,

295 and that all information shared during the interview was confidential. After having constructed

296 their previous day, participants were given the opportunity to review their previous day again,

297 and add, delete or alter activities if necessary.

298 Conflict mapping. Next, possible conflicts that arose that day were assessed. Although 299 measures focusing on goal inter-relations and goal interference are existent, none of them focus 300 on the assessment of goal conflict in humans. Our definition of goal conflict was informed by the 301 theoretical accounts of goal conflict by Lewin (1935) and Miller (1944). In these accounts, goal 302 conflict is defined as a situation in which the pursuit of one activity or goal competes with the 303 attainment of another, equally valued goal, and which creates at least a temporary stalemate, 304 characterized by an indecisiveness and hesitancy before deciding which activity to pursue (Miller, 305 1944). Patients were provided a definition of goal conflict, and further examples and information. 306 The instructions regarding goal conflict were iteratively developed in collaboration with a group 307 of (pain research) experts and were extensively piloted with patients.

308 The information provided to the participants about goal conflict was the following.

309 "Goal conflict is defined as the experience of indecisiveness or doubt about which of two 310 activities to pursue. Examples of conflicts are having doubts whether 'to study for an exam' or 311 'going out for drinks', 'reading a newspaper' or 'repairing a leaky faucet', or 'resting to reduce 312 pain' or 'going for dinner with friends'. This definition does not incorporate 'social conflict', 313 which is having a fight or an argument".

314 In order to ensure comprehensibility, participants were asked to provide an example that 315 fitted the definition above. Further clarification was given if needed. Participants were then 
316 asked to report the conflicts experienced during the previous day. Further information

317 concerning these conflicts was obtained, such as the type of activities involved, the context,

318 reasons of conflict, duration, and decision.

319 Thirty-one out of $40(77.5 \%)$ patients and 32 out of $37(86.49 \%)$ controls reported at least

320 one conflict. Nine out of $40(22.5 \%)$ patients and 5 out of 37 (13.51\%) controls did not report

321 any conflicts.

322 Goal categorization. After having reported all conflicts, these conflicts were examined

323 more closely. Participants were asked to classify the goal underlying each activity of goal

324 conflicts using the following goal category system (Chulef, Read \& Walsh, 2001):

325 1) Interpersonal/Social: the goal is to maintain or improve contact or relationships with

326 other people (e.g., going out with friends);

327 2) Intrapersonal: the goal is to maintain or improve personal qualities or personal 328 growth (e.g., be helpful);

329 3) Work/Education: the goal is related to work and/or educational purposes, and is aimed at the personal (academic) career (e.g., following classes, meeting deadlines);

4) Household: the goal is to pursue household activities or chores, and is aimed at maintaining or improving your household (e.g., having a clean house);

5) Leisure: the goal is to relax or to enjoy yourself, mostly the goal is to pursue activities that are aimed at things you do in your spare time (e.g., hobbies);

6) Financial: the goal is to maintain or improve your financial status, freedom, independence, security or stability; 
7) General physical and mental health: the goal is to maintain or improve your general physical and/or mental health, e.g., eating healthy food, stress reduction; with the exception of the goal to avoid, reduce or control pain;

8) Pain control, avoidance and/or reduction: the goal is to control, avoid or reduce pain, e.g., resting, avoiding movements, taking medication; and

9) Other: if the goal does not fit in one of the other categories, this category can be selected.

Participants were informed that only one goal per activity could be selected. If multiple categories were possible, participants should select the most important one. The list of the goal categories was placed in front of the participant as a reminder. The interviewer also illustrated how to classify the goals of the activities using an example: "Imagine sitting in a restaurant and doubting between staying for a chat with your friend, or going back to work. You may want to chat with your friend because you want to invest in the relationship with your friend. This can be placed in the category "social/interpersonal". You may want to go back to work because you wish to do the work you are meant to do; this can be classified in the category "work/education". However, it is also possible that you wish to go back to work because you want to be a professional and hard-working person, which can be classified in the category "intrapersonal". Another goal you may have, is to obtain a financial bonus; this can be placed in the category "financial". Since multiple goals are present, you have to pick the one that was most applicable in that situation, for example, "work". " 
360 allows to identify the type of goal conflict; for example: pain (control/avoidance/reduction) vs.

361 financial. For the purposes of this study, we will refer to a pain-related goal conflict if a pain

362 avoidance/control/reduction is identified as the underlying goal in a goal conflict.

363 Conflict assessment. After the goal classification of each conflict, participants were

364 asked to assess a maximum of three conflicts. In case more than three conflicts were reported,

365 the conflicts were selected at random (using a randomization table). As there were two patients

366 reporting more than three conflicts and 4 patients reporting more than three conflicts, there was

367 no data collection for 2 conflicts in patients and 8 conflicts in controls.

368

369

Questions regarding goal conflict involved conflict strength ("How strongly did you experience this conflict?"), worry ("To what extent did you worry during this conflict?"), painrelated worry ("To what extent did you worry about pain during this conflict?"), stress ("To what extent did you feel stressed during this conflict?"), need of support ("To what extent did you need support during this conflict?"), conflict solution (“How difficult was it to solve this conflict?") and solution satisfaction ("How satisfied were you with the solution of this conflict?"). relaxation, frustration). All questions were assessed on a 7-point scale going ( $0=$ not at all; 6

$377=$ very much). We ran a principal component analysis on these 11 affect-items. The scree plot analysis revealed 2 factors with an eigenvalue greater than 1 explaining $74.24 \%$ of the variance.

379 The factors created as a result of the factor analysis were 1) positive affect, which comprises the 380 variables happy, enthusiastic, and relaxed; and 2) negative affect, which comprises the variables 381 sad, nervous, irritated, angry, afraid, powerless, frustrated, and helpless. 


\section{$3 \quad$ Results}

384 Statistical analyses were performed using SPSS 23.0 and Microsoft ${ }^{\circledR}$ Excel 2010. Alpha was set 385 at .05 .

386 The key questions addressed in this paper are:

387 1. Do patients experience more goal conflict than healthy participants?

2. Do patient and healthy participants differ in the type of conflict experienced?

3. Which goals are most commonly conflicting with pain related goals?

4. Do patient and healthy participants differ in the experience and context of conflict?

5. Can core constructs of the Fear-Avoidance model or individual differences predict the

\section{3.1 Do patients experience more goal conflict than healthy participants?} The primary objective of this study was to determine the presence of goal conflict in a patient sample and in controls, and investigate whether both groups differ in the frequency of goal conflicts. For this comparison Mann-Whitney U tests were used because the assumption of normality was violated. Patients on average reported $1.53 \pm 1.13$ goal conflicts (range: $0-4)$. The total number of conflicts reported by patient participants was 61 . Nine patients did not report any conflicts. Control participants reported on average $1.87 \pm 1.46$ goal conflicts (range of $0-7$ ). Five

401 controls did not report any conflicts. The total number of conflicts reported by control 402 participants was 69. There was no significant difference in the number of conflicts between 403 patients and controls $(U=665.5, p=.431)$. Figure 1 presents the number of participants 
404 reporting either no, 1, 2, 3, or more than 3 goals as a function of group.

405

406

407

408

409

410

411

412

413

414

415

416

418

419

420

421

422

423

424

425

426

-INSERT FIGURE 1 ABOUT HERE -

\subsection{Do patient and healthy participants differ in the type of conflict experienced?}

Another aim was to explore whether patients and controls differ in the type of conflicts experienced. More specifically, a motivational account of the Fear-Avoidance model posits that pain-avoidance goals may compete with other goals in patients with chronic pain. Therefore, we expected that patients experience more pain-related goal conflict than control participants. We assessed whether patients report certain types of conflict more often than control participants. For this purpose, we calculated the number of times that a goal category was used during the goal classification of the conflicts. This resulted in a number of endorsements for each of the nine goal categories per participant.

Mann-Whitney U tests were reported because the assumption of normality was violated.

Our tests revealed that on average, patients with fibromyalgia reported more pain-related goal conflicts than control participants, $0.875 \pm 0.991$, and $0.054 \pm 0.229$, respectively, $U=363, p \leq$ .001 . As shown in Table 1, 55\% of the patients report at least one pain-related goal conflict whereas only $5.4 \%$ of controls did. Furthermore, patients with fibromyalgia on average reported less work-related goal conflicts, $U=363, p \leq .001$, less social-related goal conflicts, $U=534.5, p$ $=.021$, and less pleasure-related goal conflicts, $U=499.5, p=.004$. Patient and control participants did not differ in the average number of health-related, finance-related, householdrelated, and intrapersonal-related goal conflicts, $p \mathrm{~s}>.05$. 
428

429

\section{W.3 Which goals are most commonly conflicting with pain-related goals?}

Subsequently, we identified the type of goal that participants reported to conflict with the

431 pain-related goal (goal of pain avoidance, control and/or reduction) competed. As mentioned 432 above, patient and control participants reported 61 and 69 goal conflicts, respectively. Of the 61 433 goal conflicts reported by patients, 35 (57.4\%) goal conflicts involved a pain-related goal, 434 whereas only 2 out of 69 (2.9\%) goal conflicts reported by control participants involved a pain435 related goal. For patients, the pain-related goal most often conflicted with household goals 436 (45.7\%), social goals (20\%), and intrapersonal goals (14.3\%). Furthermore, pain-related goals 437 conflicted with other health-related goals in $8.6 \%$ and with financial goals in $5.7 \%$ of reported 438 conflicts. For controls, the 2 pain-related goal conflicts involved pleasure goals and household 439 goals, respectively.

\section{$440 \quad 3.4 \quad$ Do patient and healthy participants differ in the experience and context of conflict?}

As contextual factors might play an important role in the experience of conflict, we compared the contexts between conflicts reported by patients and conflicts reported by healthy controls. Although we did not find any differences in terms of the number of goal conflicts, we expected that patients might experience conflicts as more aversive, and might experience more conducted on the conflict level, only participants that reported a conflict, could be included. The

447 analyses were thus run on 61 conflicts reported by 32 controls and 59 conflicts reported by 31 448 patients. 
450 where the participant was (location), whether another person caused the conflict, and how the 451 conflict was solved. The frequency and percentage of participants per group is described in Table

452 2. A conflict of a patient was experienced most often when (s)he was alone (49.2\%) or with their

453 family/partner (44.3\%). Controls were also most often alone (55\%) when experiencing a conflict.

454 The majority of conflicts reported by patients occurred at home $(86 \%)$, whereas this is less the 455 case for conflicts reported by control participants (58\%). School or work accounts for $17.4 \%$ of 456 conflicts reported by control participants. For both groups, the conflict was not initiated by others, 457 and the conflict was resolved by doing only one of the activities involved in the conflict.

In order to investigate whether patients and controls differ in the experience of conflict, and to what extent the experience of conflict varies as a function of the number of conflicts we conducted multilevel analysis (on conflicts nested within persons). More specifically, different multilevel analyses are used to explain different measures of experience of conflict (i.e., the outcome variable) as a function of the 'dummy' variable Patient (controls $=0$, patients $=1$ ), the number of conflicts (Nconflicts) and the interaction between these variables. The variables $\log ($ conflict duration), conflict strength, satisfaction, difficulty, worry, worry about pain, stress, and the positive and negative affect factors are used as outcome variables in subsequent

467 multilevel analyses. Using $\mathrm{Y}_{\mathrm{ij}}$ to represent the score of person $i$ on experience-of-conflict 468 measure $Y$ (the outcome variable) for conflict $j$, the multilevel model can be formulated as 469 follows:

$$
\mathrm{Y}_{\mathrm{ij}}=\alpha_{\mathrm{i}}+\beta_{\mathrm{p}} \text { Patient }_{\mathrm{i}}+\beta_{\mathrm{nc}} \text { Nconflicts }_{\mathrm{i}}+\beta_{\mathrm{px} \mathrm{nc}} \text { Patient }_{\mathrm{i}}^{*} \text { Nconflicts }_{\mathrm{i}}+\varepsilon_{\mathrm{ij}}
$$


472 The error term $\varepsilon_{\mathrm{ij}}$ is assumed to have a Normal distribution with mean 0 and variance $\sigma_{\varepsilon}{ }^{2}$.

473 Furthermore, to account for correlation among the responses of the same person, the model

474 includes a random intercept $\alpha_{i}$ that is assumed to have a Normal distribution with mean $\mu$ and

475 variance $\sigma_{\alpha}^{2}$. To enhance the interpretation of the regression coefficients, the number of

476 conflicts was centered using grand mean centering, so that a value of 0 represents an average

477 number of conflicts. Moreover, in each analysis the dependent variable was standardized to have

478 a mean equal to 0 and a standard deviation equal to 1 . As a result, the regression coefficient of

479 the patient dummy $\left(\beta_{\mathrm{p}}\right)$ indicates how many standard deviations the average predicted $Y$-value

480 increases for patients who reported an average number of conflicts compared to controls who

481 reported an average number of conflicts. Furthermore, the regression coefficient of the number

482 of conflicts $\left(\beta_{\mathrm{nc}}\right)$ indicates how many standard deviations the predicted average $Y$-value increases

483 when persons of the control group report one conflict more. In addition, the coefficient of the

484 interaction $\left(\beta_{\mathrm{p} \times \mathrm{nc}}\right)$ indicates the additional increase in the predicted average $\mathrm{Y}$-value for patients

485 compared to controls if the person reported one conflict more. Finally, as our sample is

486 relatively small and dependent variables are not always normally distributed, standard errors for

487 estimated parameters are calculated using bootstrapping to increase accuracy. The results of the 488 analysis are presented in Table 3.

489 The estimated coefficient for the patient dummy variable indicated that (for persons who 490 reported an average number of conflicts) patients reported to worry more during conflicts, $\beta_{p}=$ $491.304, S E=.142, p=.015$, reported to worry more about their pain, $\beta_{p}=1.11, S E=.123, p<.001$,

492 reported to be more stressed during a conflict, $\beta_{p}=.68, S E=.134, p<.001$, felt more strongly

493 that they needed support during conflicts, $\beta_{p}=.574, S E=.15, p<.001$, found their conflicts 
494 more difficult to solve, $\beta_{p}=.509, S E=.14, p<.001$, were less satisfied with how they solved 495 their conflict, $\beta_{p}=-.507, S E=.162, p<.001$, experienced less positive feelings, $\beta_{p}=-.441, S E=$ $496.133, p=.001$, and more negative feelings during the conflict, $\beta_{p}=.45, S E=.131, p=.001$.

497 Furthermore, assuming an average number conflicts was reported, it took patients longer than 498 controls to solve their conflicts, $\beta_{p}=.56, S E=.138, p<.001$. This difference between patients 499 and controls increases .346 if one conflict more is reported, $\beta_{p \times n c}=.346, S E=.122, p=.001$. 500 Lastly, assuming an average number of reported conflicts, patients reported to experience their 501 conflicts more strongly than controls, $\beta_{p}=.601, S E=.137, p<.001$. Moreover the size of this 502 effect increases .273 if persons reported one conflict more, $\beta_{p \times n c}=.273, S E=.119, p=.01$. The 503 number of conflicts did not alter the experience of conflict in either of the groups for all other 504 outcome variables.

-INSERT TABLE 3 ABOUT HERE-

\subsection{Can core constructs of the Fear-Avoidance model or individual differences predict} the number of (pain-related) goal conflicts?

511 development of pain-related fear, avoidance, and disability (Vlaeyen \& Linton, 2012; Vlaeyen et

512 al., 2009; Vlaeyen, Morley, \& Crombez, 2016), we explored whether the amount of pain-related

513 goal conflict - reflected by the number of pain-related goal conflicts — could be predicted by

514 individual differences in process outcomes - such as pain-related fear, catastrophizing, and

515 hypervigilance - individual states and traits, such as general anxiety, and individual differences 516 in disability and pain. 
518 the number of pain-related goal conflicts. Because only two control participants reported a pain-

519 related goal conflict, regressions were carried out with the patient group only $(N=40)$. Measures

520 assessing traits/states included were: positive and negative affect (PANAS), trait anxiety (STAI),

521 Depression, anxiety and stress (DASS), pain catastrophizing (PCS), pain disability (PDI),

522 hypervigilance (PVAQ), pain-related fear (PASS), and cognitive intrusions (ECIP). We also

523 assessed individual differences in disability, years of pain onset, average pain (in a week), pain

524 intensity, and hindrance by pain. We corrected for over- or under-dispersion using a quasi-

525 Poisson approach. Our results indicated that the average number of pain-related goal conflicts

526 reported by patients increased $39.6 \%$ for each increase of one standard deviation in average pain,

$527 \beta=.396\left(95 \%\right.$ CI:.013; .778), Wald $\chi^{2}=4.11, d f=1, p=.043,4.3 \%$ for every standard deviation

528 increase in anxiety (DASS), $\beta=.043$ (95\% CI:.002;.082), Wald $\chi^{2}=4.28, d f=1, p=.039$, and

$5292.5 \%$ for each increase of one standard deviation on cognitive intrusions, $\beta=.025$ (95\% CI: .006;

530.043 ), Wald $\chi^{2}=7.011, d f=1, p=.008$. A marginally significant increase of $3.3 \%$ and $3.1 \%$ in

531 the average number of pain-related conflicts reported were found for an increase of one standard

532 deviation in negative affect, $\beta=.033$ (95\% CI:-.001; .067), Wald $\chi^{2}=3.6, d f=1, p=.058$, and

533 depression, $\beta=.031$ (95\% CI:-.002; .064), Wald $\chi^{2}=3.29, d f=1, p=.07$, respectively. None of

534 the other individual difference variables predicted the number of pain-related goal conflicts: Pain

535 catastrophizing: $\beta=.018(95 \% \mathrm{CI}:-.011 ; .047)$, Wald $\chi^{2}=1.52, d f=1, p=.218$; positive affect: $\beta$

$536=-.025$ (95\% CI:-.078; .029), Wald $\chi^{2}<1, d f=1, p=.365$; trait anxiety: $\beta=.017$ (95\% CI: -.013;

$.048)$, Wald $\chi^{2}=1.21, d f=1, p=.272$; stress (DASS): $\beta=.023(95 \%$ CI: $-.011 ; .056)$, Wald $\chi^{2}=$

$1.79, d f=1, p=.181$; Pain disability: $\beta=.02$ (95\% CI:-.011; .051), Wald $\chi^{2}=1.56, d f=1, p=$

539.212 ; hypervigilance: $\beta=.022$ (95\% CI:-.006; .050), Wald $\chi^{2}=2.35, d f=1, p=.125$; Pain-related 
540 fear: $\beta=.010$ (95\% CI:-.002; .023), Wald $\chi^{2}=2.72, d f=1, p=.099$; disability: $\beta=-.093(95 \%$

541 CI:.-835;.649), Wald $\chi^{2}<1, d f=1, p=.806$; years of pain onset: $\beta=-.017$ (95\% CI:-.050; .017),

542 Wald $\chi^{2}<1, d f=1, p=.323$; pain intensity: $\beta=.186(95 \%$ CI: $-.204 ; .576)$, Wald $\chi^{2}<1, d f=1, p$

$543=.351$; hindrance by pain: $\beta=.244$ (95\% CI:-.082; .530), Wald $\chi^{2}=2.06, d f=1, p=.151$.

544

545

546

547

548

549

550

551

552

553

554

555

556

557

558

559

560

561

562

\section{Discussion}

This study investigated the presence and experience of goal conflicts in patients with fibromyalgia in comparison to healthy controls. For this purpose, 40 patients with fibromyalgia and 37 healthy participants completed a semi-structured interview in which they identified experienced goal conflicts, assessed the experience of the conflict, classified each of their goals in pre-defined categories, and assessed their previous day.

First, we expected patients with fibromyalgia to report more goal conflict than control participants. Both patient and control participants were readily able to report and identify goal conflict. When asked for an example, participants spontaneously reported on personal experiences. These examples often included recurring experiences - patients with fibromyalgia mostly describing conflicts between resting in order to control/reduce pain and doing household chores or going out with friends/family_or examples of great value to the participant (e.g., being able to watch over the grandchildren daily or creating artworks out of ceramic). Nevertheless, our results revealed that patients with fibromyalgia did not spontaneously report more goal conflicts than healthy controls. This finding is not in line with the finding of Karoly and colleagues (2008). Second, we expected pain patients and controls to differ in the type of conflicts they experience. More specifically, we expected that patients' goal conflicts would include pain avoidance and control more often than those of controls. Indeed, we observed that 
563 patients reported more pain-related conflicts than controls. Additionally, patients also reported

564 less conflicts related to work, social, or pleasure goals. Of all conflicts reported by patients,

$56557.4 \%$ involved a pain-goal. Pain goals most often conflicted with household goals (45.7\%),

566 social goals $(20 \%)$ and intrapersonal goals $(14.3 \%)$. These differences in type of conflict as well

567 as the goals conflicting with pain goals might be due to contextual characteristics, as the

568 participants in our study were mostly women, unemployed and/or receiving disability benefits.

569 For example, patients reporting less work related goal conflict is possibly due to the fact that the

570 majority of patients are unemployed. Another possibility is that patients with fibromyalgia

571 construct their environment in such a way, that less conflict can arise. Similarly, it may be that

572 individuals structure their environment in such a way that they experience as little conflict as

573 possible; or that a recall bias is present, maybe resulting in reporting conflicts pertaining to life

574 domains important to the individual. Therefore, as patients' lives may be predominantly focused

575 on pain, they may experience (and report) less conflict in other domains. Our study is one of the

576 first to reveal the presence of pain-related goal conflicts, and provides preliminary evidence that

577 pain goals conflict with other goals in the daily life of patients. As such, the inclusion of a broad

578 motivational perspective in the Fear-Avoidance model is warranted (Crombez et al., 2012;

579 Vlaeyen \& Linton, 2012; Vlaeyen et al., 2016).

580 Third, another aim was to study the contextual characteristics and the affective

581 experience of the conflict. Regarding the contextual characteristics, our findings demonstrate that

582 patients experienced most conflicts at home $(86 \%)$, whereas this is less the case for control

583 participants $(58 \%$ ) - who also reported experiencing conflicts at work/school or when on their

584 way - , which again may be due to the low employment rate and disability benefits of our patient

585 sample. Both groups reported that they most often experienced a conflict when they were alone. 
586 Furthermore, despite the absence of a difference in the number of conflicts they report, patients

587 and controls differed in how they perceive conflict. Overall, it seems that patients experienced

588 conflicts more negatively than controls: they reported less positive and more negative feelings,

589 worried more, felt more stress, and felt more need for support than controls. Patients also

590 perceived their conflicts as more difficult to solve than control participants, and they reported

591 that it took them longer to solve their conflicts. Lastly, patients were on average less satisfied

592 with how they solved their conflicts than control participants. Interestingly, the number of

593 conflicts a participant experienced had little to no impact on the experience of conflict. Our

594 findings are in line with those of Hardy and colleagues (2011), who studied the relation between

595 goal conflict and fatigue and pain in a sample of 27 females with fibromyalgia. These women

596 were asked to assess pain, distress, and fatigue in the morning and in the evening, and rated their

597 goals and goal conflict in the evening for five consecutive days. They found that pain increased

598 more from morning to evening on days with higher conflict, and women with more symptoms

599 reported more goal conflict than women with fewer symptoms. Taken together, our findings

600 suggest that goal pursuit, and more specifically, goal pursuit in the face of pain, may deplete

601 resources in an already vulnerable population, which may in turn result in more pain and fatigue,

602 or feeling more hampered by it. However, further scientific inquiry is needed to explicitly test

603 these relationships.

604 The last aim of the current study was to investigate whether individual differences in

605 disability, pain, and core constructs of the Fear-Avoidance model could predict differences in the 606 amount of pain-related goal conflict. First, we found that higher average pain intensity was

607 associated with a strong increase in the reported number of pain-related conflicts of patients. As

608 these results are correlational in nature, this might indicate that experiencing intense pain may 
609 lead to more goal conflict, or conversely, that conflict leads to an increase in pain (Hardy,

610 Crofford \& Segerstrom, 2011). The relation between pain intensity and the experience of goal

611 conflict warrant further scrutiny. Second, we found that the number of pain-related goal conflicts

612 was associated with a higher number of cognitive intrusions (Attridge et al., 2015) as well as

613 more anxiety (Antony et al., 1998; de Beurs, van Dyck, Marquenie, Lange, \& Blonk, 2001; P. F.

614 Lovibond \& Lovibond, 1995). Given the importance of pain-related fear and catastrophizing in

615 the Fear-Avoidance model, we also expected that the greater pain-related fear, and the more

616 catastrophizing, the more conflicts patients would experience. However, our study was unable to

617 demonstrate an impact of pain-related fear, pain catastrophizing, pain disability, or vigilance.

618 The day reconstruction method resulted in a large database. We have only focused on the effects

619 of the frequency (number) of conflicts. Other analyses are also possible. For example, it may be

620 that these constructs not necessarily predict the number of pain-related conflicts, but the

621 characteristics of the experienced conflict. Further research is needed to investigate this

622 hypothesis. Also of importance, is that the number of outcome variables is rather large, and that

623 they might be (strongly) related to each other. It might therefore be useful to investigate which

624 variables are closely related and reliably reflect the impact of goal conflict. Nonetheless, our

625 results demonstrate that expanding the Fear-Avoidance model with a broad motivational

626 perspective may be fruitful. Our findings indicate that goal conflict or competition in chronic

627 pain is related to the interpretation of a situation as catastrophic, fueled by cognitive intrusions

628 and anxiety. Another intriguing question is whether the characteristics of pain-related conflicts

629 differ from the characteristics of non-pain-related conflicts. This question requires an analysis of

630 the type of goal conflict within subjects. Unfortunately, this analysis was not feasible, because 
631 only a limited number of pain and non-pain related goal conflicts was reported, resulting in

632 insufficient power to conduct those analyses on the current dataset.

633 This study may have clinical implications. The results underscore the importance of the

634 inclusion of goal dynamics in our understanding of chronic pain problems (Crombez et al., 2012;

635 Vlaeyen \& Linton, 2012; Vlaeyen et al., 2009), and provide evidence for the use of treatments

636 focusing on idiosyncratic goal pursuit in other domains aside from pain control and avoidance to

637 improve patients overall well-being and increase physical activity (e.g., Motivational

638 interviewing; Ang, Kesavalu, Lydon, Lane, \& Bigatti, 2007; Jensen, Nielson, \& Kerns, 2003,

639 Self-control improvement; Inzlicht, Schmeichel, \& Macrae, 2014). In this paper, we focused on

640 the presence and experience of goal conflicts in a patient sample. Therefore, we only reported if

641 participants pursued none, only one or both goals, but not which specific goal was pursued.

642 Future research might want to assess to what extent patients pursue pain avoidance at the

643 expense of other goals. Our own experience while conducting the interviews suggests that pain

644 avoidance often prevails over other activities, although this was not always the case. Therefore,

645 we suggest that future research investigates whether patients focus on one strategy - that is,

646 prioritizing pain avoidance over other activities - when repeatedly being confronted with a

647 particular type of goal conflict.

Additionally, it might be appropriate to screen for certain individual characteristics such

649 as general anxiety, as these individuals might benefit more from a tailored treatment strategy,

650 since our research suggested that these individuals might experience more pain-related goal

651 conflicts. However, more insight is needed on which patients experience more goal interference

652 than others, or for which patients pain-related goal conflicts weighs more on their physical and 653 psychological well-being. 

no cause-effect relationships can be discerned. Therefore, caution is warranted when interpreting 656 the results. Second, this study is one of the first of its kind, and largely exploratory in nature. 657 Further research is needed to replicate and extend our findings. Third, the day reconstruction 658 method generated a large database. To assess the impact of personal characteristics (e.g., fear of pain), we focused on predicting the number of conflicts. However, other analyses are also possible, and we encourage the use of our database for secondary analyses. Also, a large number of (outcome) variables was collected, which may be dependent. This should be taken into account when looking at the different analyses reported here, or when performing secondary analyses. Fourth, our study sample was limited to patients with fibromyalgia. Therefore, we need to be careful in generalizing our findings to other pain syndromes.

665

666

667

668

\section{Conclusions}

This study provides more insight in the dynamic relations between pain-related and other

671 goals and their impact on daily life. At the same time they provide a good starting point to

672 further study the impact of pain-related goal conflict in patients with chronic pain. It seems that 673 goals competing for resources differ between patients and controls, with a more prominent role

674 for pain-avoidance and - control in the lives of patients. Furthermore, our results suggest that 675 patients experience conflict more aversively than healthy controls. However, further scientific 
676 inquiry is required to uncover the potential detrimental impact of pain-related goal conflict on

677 daily life experience.

678

679

Acknowledgements

680 The authors thank Eveline Demeulemeester, Julie Mengé, and Nele Decoene for their help in 681 data acquisition and Annick De Paepe for her collaboration. We would also like to thank the

682 Multidisciplinary Pain Centre of Ghent University Hospital, especially prof. dr. Jacques 683 Devulder, for their help with the recruitment of patients with fibromyalgia. The data of this paper 684 was partially presented during the $10^{\text {th }}$ Congress of the European Pain Federation EFIC, 685 September 6-9, 2017 in Copenhagen, Denmark. 
686

687

688

689

690

691

692

693

694

695

696

697

698

699

700

701

702

703

704

705

706

707

708

\section{References}

Ang D., Kesavalu R., Lydon JR., Lane KA., Bigatti S. 2007. Exercise-based motivational interviewing for female patients with fibromyalgia: a case series. Clinical Rheumatology 26:1843-1849. DOI: 10.1007/s10067-007-0587-0.

Antony MM., Bieling PJ., Cox BJ., Enns MW., Swinson RP. 1998. Psychometric properties of the 42-item and 21-item versions of the Depression Anxiety Stress Scales in clinical groups and a community sample. Psychological Assessment 10:176-181. DOI: 10.1037/10403590.10.2.176.

Attridge N., Crombez G., Van Ryckeghem D., Keogh E., Eccleston C. 2015. The Experience of Cognitive Intrusion of Pain. PAIN 156:1978-1990. DOI: 10.1097/j.pain.0000000000000257.

Boudreaux MJ., Ozer DJ. 2012. Goal conflict, goal striving, and psychological well-being. Motivation and Emotion 37:433-443. DOI: 10.1007/s11031-012-9333-2.

Burns JW., Mullen JT., Higdon LJ., Wei JM., Lansky D. 2000. Validity of the Pain Anxiety Symptoms Scale (PASS): Prediction of physical capacity variables. Pain 84:247-252. DOI: 10.1016/S0304-3959(99)00218-3.

Chulef AS., Read SJ., Walsh DA. 2001. A hierarchical taxonomy of human goals. Motivation and Emotion 25:191-232. DOI: 10.1023/A:1012225223418.

Claes N., De Paepe A., Decoene N., Lauwerier E., Legrain V., Vlaeyen J., Crombez G. 2015. Pain-attention-motivation project 1 (PAM-I): protocol. Available at https://ib.ugent.be/catalog/pug01:7032736

Crombez G., Eccleston C., Baeyens F., Eelen P. 1998. When somatic information threatens, catastrophic thinking enhances attentional interference. Pain 75:187-98.

Crombez G., Eccleston C., Van Damme S., Vlaeyen JWS., Karoly P. 2012. Fear-avoidance 
model of chronic pain: the next generation. The Clinical journal of pain 28:475-83. DOI:

710 10.1097/AJP.0b013e3182385392.

711 de Beurs E., van Dyck R., Marquenie L., Lange A., Blonk RWB. 2001. De DASS; een

712 vragenlijst voor het meten van depressie, angst en stress. [The DASS: a questionnaire for 713 measuring depression, anxiety, and stress]. Gedragstherapie 34:35-53.

714 Emmons RA., King LA. 1988. Conflict among personal strivings: immediate and long-term 715 implications for psychological and physical well-being. Journal of personality and social psychology 54:1040-8.

717 Engelen U., De Peuter S., Victoir A., Van Diest I., Van Den Bergh O. 2006. Further validation of

718 the Positive and Negative Affect Schedule (PANAS) and comparison of two Dutch versions.

719 Gedrag en Gezondheid 34:61-70.

720 Geenen R., Jacobs JWG. 2010. De nieuwe diagnostische criteria voor fibromyalgie. [The new diagnostic criteria for fibromyalgia]. Nederlands tijdschrift voor reumatologie 4:52-54.

722

723

724

725

726

727

728

729

730

731

Gorges J., Esdar W., Wild E. 2014. Linking goal self-concordance and affective reactions to goal conflict. Motivation and Emotion 38:475-484. DOI: 10.1007/s11031-014-9392-7.

Hardy JK., Crofford LJ., Segerstrom SC. 2011. Goal conflict, distress, and pain in women with fibromyalgia: a daily diary study. Journal of psychosomatic research 70:534-40. DOI: 10.1016/j.jpsychores.2010.10.013.

Inzlicht M., Schmeichel BJ., Macrae CN. 2014. Why self-control seems (but may not be) limited. Trends in Cognitive Sciences 18:127-133. DOI: 10.1016/j.tics.2013.12.009.

Jensen MP., Nielson WR., Kerns RD. 2003. Toward the development of a motivational model of pain self-management. The Journal of Pain 4:477-492. DOI: 10.1016/S15265900(03)00779-X. 
732 Kahneman D., Krueger AB., Schkade DA., Schwarz N., Stone AA. 2004. A survey method for

733 characterizing daily life experience: the day reconstruction method. Science 306:1776-80.

734 DOI: $10.1126 /$ science. 1103572.

735 Karoly P., Okun MA, Ruehlman LS., Pugliese JA. 2008. The Impact of Goal Cognition and Pain

736 Severity on Disability and Depression in Adults with Chronic Pain: An Examination of

737 Direct Effects and Mediated Effects via Pain-Induced Fear. Cognitive Therapy and

$738 \quad$ Research 32:418-433. DOI: 10.1007/s10608-007-9136-z.

739 Von Korff M., Ormel J., Keefe FJ., Dworkin SF. 1992. Grading the severity of chronic pain.

740 Pain 50:133-149. DOI: 10.1016/0304-3959(92)90154-4.

741 Lauwerier E., van Damme S., Goubert L., Paemeleire K., Devulder J., Crombez G. 2012. To

742 control or not? A motivational perspective on coping with pain. Acta Neurologica Belgica

743 112:3-7. DOI: $10.1007 / \mathrm{s} 13760-012-0020-6$.

744 Leeuw M., Goossens MEJB., Linton SJ., Crombez G., Boersma K., Vlaeyen JWS. 2007. The

745 fear-avoidance model of musculoskeletal pain: current state of scientific evidence. Journal

746 of behavioral medicine 30:77-94. DOI: 10.1007/s10865-006-9085-0.

747 Lewin K. 1935. A dynamic theory of personality. New York: McGraw-Hill.

748 Lovibond SH., Lovibond PF. 1995a. Manual for the Depression Anxiety Stress Scales. Sydney,

749 Austriala: Psychology Foundation of Austriala.

750 Lovibond PF., Lovibond SH. 1995b. The structure of negative emotional states: Comparison of

751 the depression anxiety stress scales (DASS) with the Beck Depression and Anxiety

752 Inventories. Behaviour Research and Therapy 33:335-343. DOI: 10.1016/0005-

$753 \quad 7967(94) 00075-\mathrm{U}$.

754 Mccracken LM. 1997. "Attention” to Pain in Persons With Chronic Pain : A Behavioral 
Approach. Behavior Therapy 28:271-284.

756

757

758

759

760

761

762

763

764

765

766

767

768

769

770

771

772

773

774

775

776

777

McCracken LM., Zayfert C., Gross RT. 1992. The pain anxiety symptoms scale: development and validation of a scale to measure fear of pain. Pain 50:67-73. DOI: 10.1016/03043959(92)90113-P.

Miller NE. 1944. Experimental studies of conflict. In: Hunt JM ed. Personality and behavior disorders. New York: The Ronald Press Company, 431-464.

POLLARD CA. 1984. Preliminary validity study of the pain disability index. Perceptual and Motor Skills 59:974-974. DOI: 10.2466/pms.1984.59.3.974.

Riediger M., Freund AM. 2004. Interference and facilitation among personal goals: differential associations with subjective well-being and persistent goal pursuit. Personality \& social psychology bulletin 30:1511-23. DOI: 10.1177/0146167204271184.

Roelofs J., McCracken LM., Peters ML., Crombez G., van Breukelen G., Vlaeyen JWS. 2004. Psychometric evaluation of the pain anxiety symptoms scale (PASS) in chronic pain patients. Journal of Behavioral Medicine 27:167-183. DOI: 10.1023/B:JOBM.0000019850.51400.a6.

Roelofs J., Peters ML., McCracken L., Vlaeyen JWS. 2003. The pain vigilance and awareness questionnaire (PVAQ): Further psychometric evaluation in fibromyalgia and other chronic pain syndromes. Pain 101:299-306. DOI: 10.1016/S0304-3959(02)00338-X.

Roelofs J., Peters ML., Muris P., Vlaeyen JWS. 2002. Dutch version of the Pain Vigilance and Awareness Questionnaire: Validity and reliability in a pain-free population. Behaviour Research and Therapy 40:1081-1090. DOI: 10.1016/S0005-7967(02)00008-6.

Segerstrom SC., Solberg Nes LS. 2006. When Goals Conflict But People Prosper: The Case of Dispositional Optimism. Journal of research in personality 40:675-693. DOI: 


$$
\text { 10.1016/j.jrp.2005.08.001. }
$$

779 Spielberger CD., Gorsuch R., Lushene R. 1970. State-Trait Anxiety Inventory. Palo Alto, CA:

$780 \quad$ Consulting Psychologists Press.

781 Sullivan MJL., Bishop SR., Pivik J. 1995. The Pain Catastrophizing Scale: Development and 782 validation. Psychological Assessment 7:524-532. DOI: 10.1037//1040-3590.7.4.524.

783 Tait RC., Chibnall JT., Krause S. 1990. The Pain Disability Index: Psychometric properties. Pain 784 40:171-182. DOI: 10.1016/0304-3959(90)90068-O.

785

786

787

788

789

790

791

792

793

794

795

796

797

798

799

800

Van Damme S., Crombez G., Bijttebier P., Goubert L., Van Houdenhove B. 2002. A confirmatory factor analysis of the Pain Catastrophizing Scale: invariant factor structure across clinical and non-clinical populations. Pain 96:319-24.

Van Damme S., Crombez G., Eccleston C. 2008. Coping with pain: a motivational perspective. Pain 139:1-4. DOI: 10.1016/j.pain.2008.07.022.

Van der Ploeg HM. 1980. Validity of the Zelf-Beoordelings-Vragenlijst (A Dutch Version of the Spielberger State-Trait Anxiety Inventory). Nederlands Tijdschrift voor de Psychologie en haar Grensgebieden 35:243-249.

Vlaeyen JWS., Crombez G., Linton SJ. 2009. The fear-avoidance model of pain: We are not there yet. Comment on Wideman et al. "A prospective sequential analysis of the fearavoidance model of pain" [Pain, 2009] and Nicholas "First things first: reduction in catastrophizing before fear of movement" . Pain 146:222; author reply 222-3. DOI: 10.1016/j.pain.2009.08.022.

Vlaeyen JW., Linton SJ. 2000. Fear-avoidance and its consequences in chronic musculoskeletal pain: a state of the art. Pain 85:317-32.

Vlaeyen J., Linton SJ. 2012. Fear-avoidance model of chronic musculoskeletal pain: 12 years on. 
801 Pain 153:1144-7. DOI: 10.1016/j.pain.2011.12.009.

802 Vlaeyen JWS., Morley S., Crombez G. 2016. The experimental analysis of the interruptive, 803 interfering, and identity-distorting effects of chronic pain. Behaviour Research and Therapy $804 \quad$ 86:23-34. DOI: 10.1016/j.brat.2016.08.016.

805 Watson D., Clark LA., Tellegen A. 1988. Development and validation of brief measures of 806 positive and negative affect: the PANAS scales. Journal of personality and social $807 \quad$ psychology 54:1063-70.

808 Wertli MM., Rasmussen-Barr E., Weiser S., Bachmann LM., Brunner F. 2014. The role of fear 809 avoidance beliefs as a prognostic factor for outcome in patients with nonspecific low back 810 pain: a systematic review. The Spine Journal 14:816-836.e4. DOI:

$811 \quad$ 10.1016/j.spinee.2013.09.036.

812 Wolfe F., Clauw DJ., Fitzcharles M-AA., Goldenberg DL., Katz RS., Mease P., Russell AS.,

813 Russell IJ., Winfield JB., Yunus MB. 2010. The American College of Rheumatology

814 preliminary diagnostic criteria for fibromyalgia and measurement of symptom severity.

815 Arthritis care \& research 62:600-10. DOI: 10.1002/acr.20140.

816 Zale EL., Lange KL., Fields SA., Ditre JW. 2013. The relation between pain-related fear and 817 disability: a meta-analysis. The journal of pain : official journal of the American Pain $818 \quad$ Society 14:1019-30. DOI: 10.1016/j.jpain.2013.05.005.

819 


\section{Table $\mathbf{1}$ (on next page)}

Frequency and percentage of participants reporting pain-related goal conflict 
Table 1

Frequency and percentage of participants reporting pain-related goal conflict

\begin{tabular}{ccccccccc} 
number of pain-related & \multicolumn{2}{c}{ Total $(\mathrm{N}=77)$} & & \multicolumn{2}{c}{ Patients $(\mathrm{N}=40)$} & & \multicolumn{2}{c}{ Controls $(\mathrm{N}=37)$} \\
\cline { 2 - 3 } conflicts & $N$ & $\%$ & & $N$ & $\%$ & & $N$ & $\%$ \\
\hline $\mathbf{0}$ & 53 & 68.8 & & 18 & 45 & & 35 & 94.6 \\
$\mathbf{1}$ & 14 & 18.2 & & 12 & 30 & & 2 & 5.4 \\
$\mathbf{2}$ & 8 & 10.4 & & 8 & 20 & & 0 & 0 \\
$\mathbf{3}$ & 1 & 1.3 & & 1 & 2.5 & & 0 & 0 \\
$>\mathbf{3}$ & 1 & 1.3 & & 1 & 2.5 & & 0 & 0 \\
\hline
\end{tabular}




\section{Table 2 (on next page)}

Frequency and percentage of conflicts per group for the variables who, location, cause, and conflict solution 


\section{Manuscript to be reviewed}

Table 2

Frequency and percentage of conflicts per group for the variables who, location, cause, and conflict solution

\begin{tabular}{|c|c|c|c|c|c|c|}
\hline & \multicolumn{2}{|c|}{ Total } & \multicolumn{2}{|c|}{ Patients } & \multicolumn{2}{|c|}{ Controls } \\
\hline & $N$ & $\%$ & $N$ & $\%$ & $N$ & $\%$ \\
\hline \multicolumn{7}{|l|}{ Who } \\
\hline alone & 68 & 52.3 & 30 & 49.2 & 38 & 55.1 \\
\hline family/partner & 45 & 34.6 & 27 & 44.3 & 18 & 26.1 \\
\hline friends/acquaintances & 4 & 3.1 & 0 & 0 & 4 & 5.8 \\
\hline colleagues/fellow students & 5 & 3.8 & 0 & 0 & 5 & 7.2 \\
\hline other & 4 & 3.1 & 2 & 3.3 & 2 & 2.9 \\
\hline multiple categories & 4 & 3.1 & 2 & 3.3 & 2 & 2.9 \\
\hline \multicolumn{7}{|l|}{ Location } \\
\hline at home & 93 & 71.5 & 53 & 86.9 & 40 & 58 \\
\hline on the way & 10 & 7.7 & 3 & 4.9 & 7 & 10.1 \\
\hline visiting family/friends/acquaintances & 4 & 3.1 & 0 & 0 & 4 & 5.8 \\
\hline work/school & 13 & 10 & 1 & 1.6 & 12 & 17.4 \\
\hline other & 10 & 7.7 & 4 & 6.6 & 6 & 8.7 \\
\hline \multicolumn{7}{|l|}{ Conflict caused by someone else } \\
\hline No & 98 & 75.4 & 44 & 72.1 & 54 & 78.3 \\
\hline Yes & 32 & 24.6 & 17 & 27.9 & 15 & 21.7 \\
\hline \multicolumn{7}{|l|}{ Conflict solution } \\
\hline Perform 1 of both activities & 85 & 65.4 & 41 & 67.2 & 44 & 63.8 \\
\hline Do both activities (sequentially) & 45 & 34.6 & 20 & 32.8 & 25 & 36.2 \\
\hline
\end{tabular}




\section{Table 3(on next page)}

Multilevel regression analyses for experience of conflict outcome variables

Note. $\mathrm{SE}=$ Standard Error, calculated using bootstrapping. $\sigma_{\mathrm{e}}{ }^{2}=$ variance of the error term; $\sigma_{\mathrm{a}}^{2}=$ variance of the random intercept. 
Table 3

Multilevel regression analyses for experience of conflict outcome variables

\begin{tabular}{|c|c|c|c|c|c|c|c|c|c|c|c|c|c|c|c|c|}
\hline \multirow[t]{4}{*}{ Outcome variable } & & & & \multicolumn{9}{|c|}{ Predictors } & \multicolumn{4}{|c|}{ Variance components } \\
\hline & & & & \multirow{2}{*}{\multicolumn{3}{|c|}{ Patient }} & \multirow{2}{*}{\multicolumn{3}{|c|}{ Number of Conflicts }} & \multirow{2}{*}{\multicolumn{3}{|c|}{ Interaction }} & \multirow{2}{*}{\multicolumn{2}{|c|}{ Error variance }} & \multirow{2}{*}{\multicolumn{2}{|c|}{$\begin{array}{l}\text { variance random } \\
\text { intercept }\end{array}$}} \\
\hline & \multicolumn{3}{|c|}{ Mean random intercept } & & & & & & & & & & & & & \\
\hline & $\mu$ & $S E$ & $p$ & $\beta_{p}$ & $S E$ & $p$ & $\beta_{n c}$ & $S E$ & $p$ & $\beta_{p \times n c}$ & $S E$ & $p$ & $\sigma_{\varepsilon}^{2}$ & $p$ & $\sigma_{\alpha}^{2}$ & $p$ \\
\hline $\log$ (duration) & -.263 & .106 & $<.005$ & .56 & .138 & $<.001$ & -.099 & .077 & .137 & .346 & .122 & .001 & .322 & .592 & .674 & $<.001$ \\
\hline Conflict strength & -.281 & .107 & .002 & .601 & .137 & $<.001$ & -.006 & .076 & .917 & .273 & .119 & .010 & .491 & .467 & .450 & $<.001$ \\
\hline Worry & -.153 & .102 & .091 & .304 & .142 & .015 & -.076 & .078 & .255 & -.015 & .129 & .902 & .481 & .475 & .529 & $<.001$ \\
\hline Worry about pain & -.566 & .073 & $<.001$ & 1.112 & .123 & $<.001$ & -.003 & .035 & .905 & -.148 & .119 & .126 & .466 & .417 & .228 & .087 \\
\hline Stress & -.335 & .097 & $<.001$ & .680 & .134 & $<.001$ & -.001 & .074 & .983 & .021 & .137 & .858 & .454 & .491 & .460 & $<.001$ \\
\hline Need for support & -.283 & .089 & .002 & .574 & .150 & $<.001$ & -.029 & .046 & .434 & .118 & .140 & .316 & .594 & .398 & .347 & .007 \\
\hline Difficulty to solve & -.256 & .095 & .003 & .509 & .140 & .001 & .084 & .080 & .218 & .001 & .146 & .987 & .531 & .420 & .419 & $<.001$ \\
\hline $\begin{array}{l}\text { Satisfaction with } \\
\text { solution }\end{array}$ & .252 & .106 & .004 & -.507 & .162 & $<.001$ & -.044 & .067 & .340 & .040 & .165 & .759 & .959 & .192 & 0 & 1 \\
\hline Positive affect & .197 & .104 & .032 & -.441 & .133 & .001 & .040 & .098 & .662 & -.159 & .160 & .256 & .376 & .503 & .632 & $<.001$ \\
\hline Negative affect & -.215 & .090 & .013 & .450 & .131 & .001 & -.030 & .058 & .549 & .194 & .124 & .073 & .290 & .464 & .675 & $<.001$ \\
\hline
\end{tabular}


Figure 1

Frequency of reported goal conflicts as a function of group

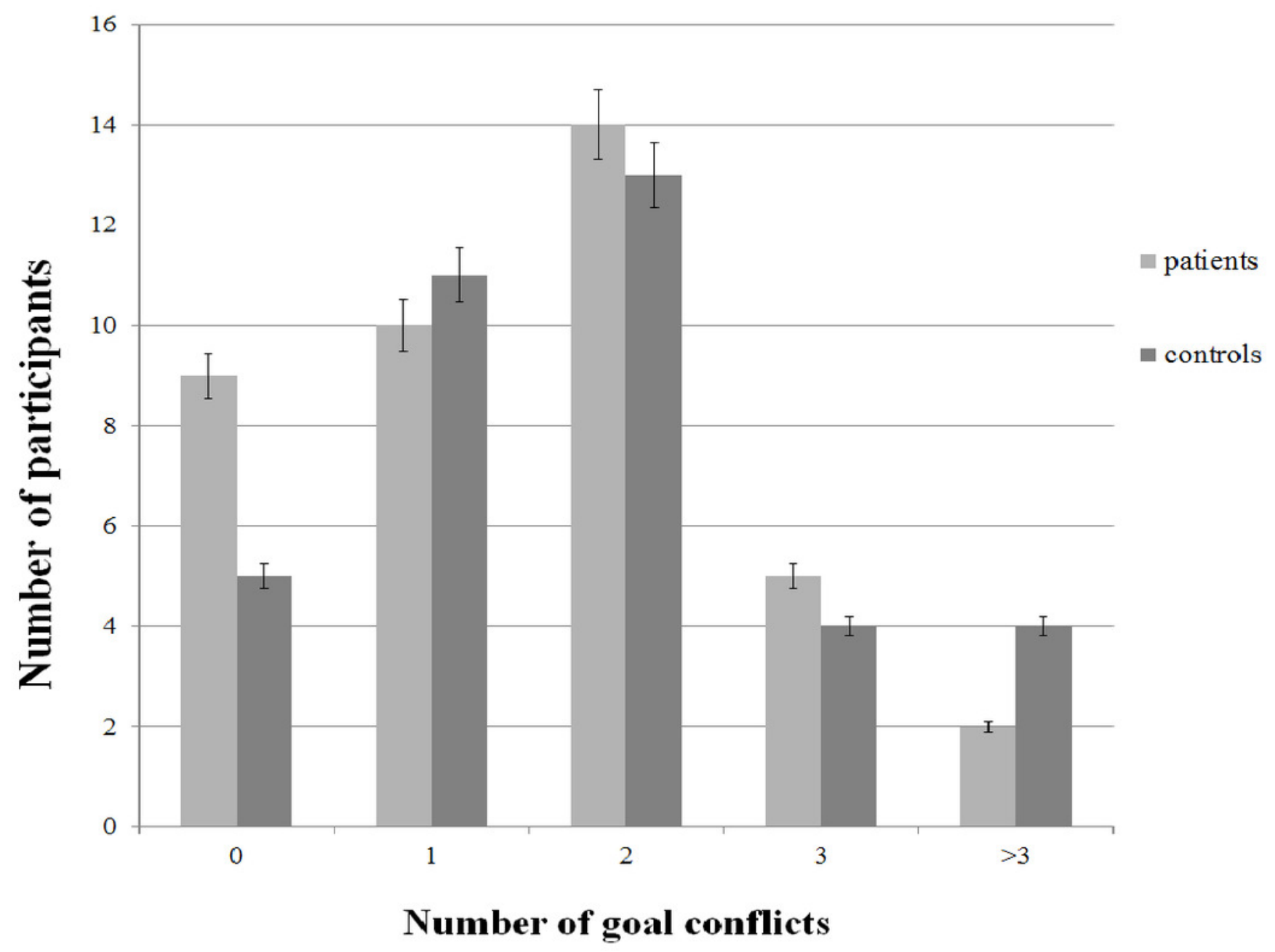

